\title{
Environmental Waste Management of Disposable Surgical Coverage
}

\author{
Milan Majerník ${ }^{1}$, Naqib Daneshjo $^{1 *}$, Peter Malega ${ }^{2}$, Zuzana Štofková ${ }^{3}$ \\ ${ }^{1}$ University of Economics in Bratislava, Faculty of Commerce, Slovak Republic \\ ${ }^{2}$ Technical University of Kosice, Faculty of Mechanical Engineering, Institute of Management, \\ Industrial and Digital Engineering, Slovak Republic \\ ${ }^{3}$ University of Žilina, Faculty of Operation and Economics of Transport and Communications, Slovak Republic
}

Received: 12 January 2021

Accepted: 13 April 2021

\begin{abstract}
The sustainable direction in the field of patient and medical staff health safety is the use of disposable medical devices, including disposable surgical masks, as recommended by the actual European standard. Disposable surgical coverage is the result of cooperation between medical professional workplaces worldwide and professionals in the area of nonwovens and lamination of material. Various variants were developed, tested and then rejected and then finally reach the material and variant composition. The use of disposable medical devices in healthcare is now a common practice, but also an environmental problem on a global scale. Despite the widespread adoption of this best practice, many healthcare facilities and patients still register resistance and scepticism against this form, actually also in connection with protection against COVID-19. The promoted opinion also by research-confirmed opinion is that the disposable form significantly reduces the amount of regulated medical waste that is generated during surgical procedures, subsequent sterilization and in the framework of protection against COVID-19. At the same time, logistical modeling of the best practice of environmental management in waste management remains a problem for the future.
\end{abstract}

Keywords: disposable surgical masks, waste management, environmental impact, COVID-19

\section{Introduction}

Protective gowns and disposable surgical masks have been used in healthcare for more than a century in all surgical procedures and patient treatments. They went through various stages of development. Once white cotton rags boiled in boiling water were enough, cleaning agents and bleaches were gradually added

*e-mail: daneshjo47@gmail.com for disinfection. Protective gowns have been and are also now used to minimize the risk of infection by the healthcare provider, to reduce the risk of infection from patient to patient and during invasive procedures to support the maintenance of a sterile field. Disposable surgical masks are used by invasive procedures to maintain the sterility of the wound, the environment and the surfaces around the patient.

Today, development has advanced from various aspects of protection, from the use of $100 \%$ natural cotton to disposable materials. In hospital facilities, it is very important to protect the health of all participants, 
not only the patient, but also the operating staff. Recent years have shown that there is an increase in protection, especially against infections such as HIV, BSE (mad cow disease), Hepatitis B and COVID-19. Another of the risk areas is postoperative complications caused by infections. Because of this fact is the protection of the patient against infections before, during and after surgery very important. In connection with the infection of the surgical place, nosocomial infection is usually reported as the third most common (about 20\%).

Due to this risk, it is now preferred to use disposable barrier textile products that provide improved barrier capabilities depending on the transfer of microorganisms. These are most often nonwovens with modifications according to the requirements of individual surgical procedures, respectively protective measures. The products used in operating rooms are divided into three basic groups: surgical clothing, surgical drapes and disposable surgical masks. New standards and regulations have been set for healthcare worldwide due to the increasing number of infectious diseases. In 2003, International Federation of Infection Control (IFIC) set minimum requirements for the prevention of surgical site infections, using barrier products. These products include disposable surgical masks and surgical gowns that are impermeable to bacteria and serve as a barrier against contamination by microorganisms in the surgical place.

Laustsen [1] in his work presented the opinion that the perioperative environment generates large amounts of waste, which negatively affects local and global ecosystems. To manage the waste health care facility leaders must focus on identifying correctable issues, work with relevant stakeholders to promote solutions, and adopt systematic procedural changes. Nurses and managers can moderate negative environmental effects by promoting reduction, recycling, and reuse of materials in the perioperative setting.

A trio authors You S., Sonne Ch. and Ok Y.S. [2] summarised the dilemma of existing plastic waste management. They highlights that it is important to adopt a sustainable, systematic, and hierarchical plastic management roadmap that clearly defines the relative roles and socioeconomic and environmental impacts of these measures. The roadmap needs to take disaster resilience as a design factor, and relevant action plans need to be plastic waste type-specific and country demand-specific and call for greater support from policymakers and the public.

In the research made by Klemes et al. [3] is clear that among the many adverse consequences of the COVID-19 pandemic is the sudden surge in the volume of plastic waste, particularly for products used for personal protection and healthcare purposes. The environmental issues are related to the life cycles of products and are measurable via metrics such as footprints (PF and PWF) highlighted in this research. The crucial priority is placed on the destruction of residual pathogens for the safe disposal of that waste.
Rhee S.W. [4] did research about management of used personal protective equipment and wastes related to COVID-19 in South Korea. To resolve the emergency situation of wastes due to COVID-19, all stakeholders should work together in cooperation with each other. Wastes related to COVID-19 such as used PPE, including masks, gloves and protective clothes in hospitals and isolated life treatment centres, should be discharged separately from other wastes by workers and managers using special containers with a red symbol. Collectors and local government should control the waste stream from collection to disposal safely.

The paper from Mihai F.C. [5] points out several critical issues related to medical and municipal waste management sectors on the example of Romania. Monitoring of COVID-19 waste flow through the proposed model is important for decision-makers, particularly in low and middle-income countries like Romania, which are facing waste management deficiencies and gaps in waste statistics, to reduce other contamination risks or related environmental threats. The mentioned recommendations would enhance better decisions across EU and Romania in mitigating the waste-related secondary impacts on public health status and environmental factors during such biologic hazards or other possible hazards (natural or anthropogenic) caused by climate change or environmental pollution.

The authors Das A., Garg R., Ojha B., Banerjee T. [6] found out that hospitals and institutions should expand their capacities to transport and store biomedical waste owing to increase in the quantity of the waste. An electronic communication mechanism should be in place to specify the exact quantity of "COVID-19 waste" in different categories, any breach during transportation and treatment that should be notified to the nodal agency. Institutional infection prevention and control team should conduct regular training of all concerned staff for biomedical waste management and monitor the practices. These steps in combination with strict adherence to the norms will ensure better handling of the impending crisis.

In the study of Sarkodie and Owusu [7] was assessed the impact of COVID-19 pandemic on waste management by observing lockdown and social distancing measures. They found that the quantity of waste increased across countries observing the social distancing measure of staying at home. The intensification of single-use products and panic buying have increased production and consumption, hence thwarting efforts towards reducing plastic pollution.

Singh et al. [8] stated that waste generation amid COVID-19, especially discarded PPEs and single-use plastics, has been an environmental and public health crisis around the world particularly in the countries with developing economies and those in transition. Generally, discarded healthcare waste and other forms of clinical waste are disposed of in a sanitary landfill or incinerated in the form of waste to energy recovery. 
From the research work that was made by Rupani P.F. et al. [9] is clear that the health waste production grows rapidly during the COVID-19 crisis which positions a vital threat to both health workers and the public, if gathered or managed inappropriately. Therefore, appropriate planning and management of the significantly growing health waste and its threat in the time of the crisis is of great importance. On the other hand, the management of the domes-tic waste during the pandemic has also raised potential environmental threats.

In the paper that wrote team led by Sharma H.B. [10], the crisis brought upon by the COVID-19 pandemic has altered global waste generation dynamics and therefore has necessitated special attention. The study presents specific cases for biomedical waste, plastic waste, and food waste management - all of which have been a major cause of concern during this crisis. The study also stresses the need for building localized resilient supply chains to counter such situations during future pandemics, while offering innovative solutions to existing waste management challenges, the study also suggests some key recommendations to the policymakers to help handle probable future pandemics if any holistically.

Research team led by Tabish M. [11] pointed out that the pandemic has resulted in substantial difficulties in the treatment of solid municipal waste and harmful medical waste. Under normal conditions, treatment systems designed for waste quality and quantity have to deal with drastic changes that cause irregular operations. Lockdown initiatives have resulted in a rise in the quantity of packaging. Such changes will intensify environmental issues with plastics that already existed before the pandemic took place. They proposed to use metrics that should create and wholly exploit to promote device design and comparison of alternatives, respectively footprints.

A trio of authors Ilyas S., Srivastava R.R. and Kim H. [12] did research about disinfection technology and strategies for COVID-19 hospital and bio-medical waste management. The personal protective equipment, testing kits, surgical facemasks, and nitrile gloves are the major contributors to waste volume. Their article presents a discharge of a new category of bio-medical waste - COVID-waste. COVID-waste is of great global concern to public health and environmental sustainability if handled inappropriately. It may cause exponential spreading of this fatal disease as waste acts as a vector for SARS-CoV-2, which survives up to 7 days on COVID-waste (like facemasks).

Zand and Heir [13] pointed in their research that the involvement of the environmental and human health effects of the COVID-19 pandemic will be inevitable in planning of sustainable solid waste management strategies for the upcoming few years. Developing countries with generally less developed waste management infrastructures are required to put significant effort into building up capacities to cope with this emerging crisis. Proposals are that for COVID-19 patients (and their family members) who receive care at home should be provided with sufficient training and their produced wastes must be collected separately in tightly closed double bags.

Nzediegwu and Chang [14] in their research proposed as a solution a special waste collection buckets that will collect disposable PPEs in buildings (residential, government and hospitals) and in public places. Trained personnel who would then decontaminate or dispose the PPE could empty such waste collection buckets, at least daily.

The team led by Peng J. [15] stated that it is recommended that all of the domestic waste and medical waste in the hospitals with concentrated admissions of confirmed patients and suspected patients should be incinerated with a disposal time less than 24 hours and a frequency of twice a day if possible.

The research paper from Rada E.C., et al. [16] considers the advantages and disadvantages of universities in terms of waste management. Specifically, setting up communication campaigns, standard procedures, monitoring actions, pricing strategies that incentivize selective collection and improving the collaboration within the university community are identified as crucial initiatives.

The research work of Cesaro A. and Pirozzi F. [17] discussed the impact of the COVID-19 emergency on both the generation and the management of solid waste originating from both household and healthcare activities. The solutions of this research presented the idea, that the emergency represents an opportunity to re-think waste management strategies, shaping them to allow greater flexibility as well as actual sustainability.

Ragazzi M. et al. [18] did research about municipal solid waste management during the SARS-COV-2. They found out that delays in the publication of guidelines on waste management impacted on the safety of the operators collecting potentially infected waste. Contrarily to expectations, single-use masks and gloves do not have significant impact on waste management, accounting for $<1 \%$ of the residual municipal solid waste collected annually. However, the dispersion of abandoned masks and gloves outside indoor environments is creating environmental problems.

Authors Yu H., Sun X., Solvang W.D. Zhao X. [19] deal with the problem of epidemic reverse logistics network for dealing with medical waste. In order to control the spread of an epidemic, the effective management of rapidly increased medical waste through establishing a temporary reverse logistics system is of vital importance. Therefore, this paper proposes a novel multi-objective multi-period mixed integer program for reverse logistics network design in epidemic outbreaks, which aims at determining the best locations of temporary facilities and the transportation strategies for effective management of the exponentially increased medical waste within a very short period. Among other insights, the results suggest installing 
temporary incinerators may be an effective solution for managing the tremendous increase of medical waste during COVID-19.

The research paper from Kumar et al. [20] deals with Life Cycle Assessment of Personal Protective Equipment kits that has been performed using $\mathrm{GaBi}$ version 8.7 under two disposal scenarios, namely landfill and incineration (both centralized and decentralized) for six environmental impact categories covering overall impacts on both terrestrial and marine ecosystems. Considering the inventories of PPE kits, disposal of PPE bodysuit has the maximum impact, followed by gloves and goggles, in terms of GWP. The use of metal strips in face-mask has shown the most significant HTP impact.

In the research study of Liu Z. et al. [21] are proposed the model and the algorithm to solve the problem of medical waste disposal, based on transit temporary storage stations, which authors are convinced will have far-reaching significance for China and other countries to dispatch medical waste in response to such public health emergencies. The two-level model and the immune algorithm-ant colony optimization-tabu search (IA-ACO-TS) algorithm were used for simulation and testing, which achieved good verification.

Prata et al. [22] pointed out that surgical masks should not be worn longer than a few hours (e.g., 3 h), and should be adequately discarded to avoid crosscontamination (i.e., in sealed plastic bags). Besides being a public health concern, incorrect disposal of PPE quickly spread in several public places and natural environments.

\section{Material and Methods}

The analysis of foreign approaches and research of environmental waste management in the technology

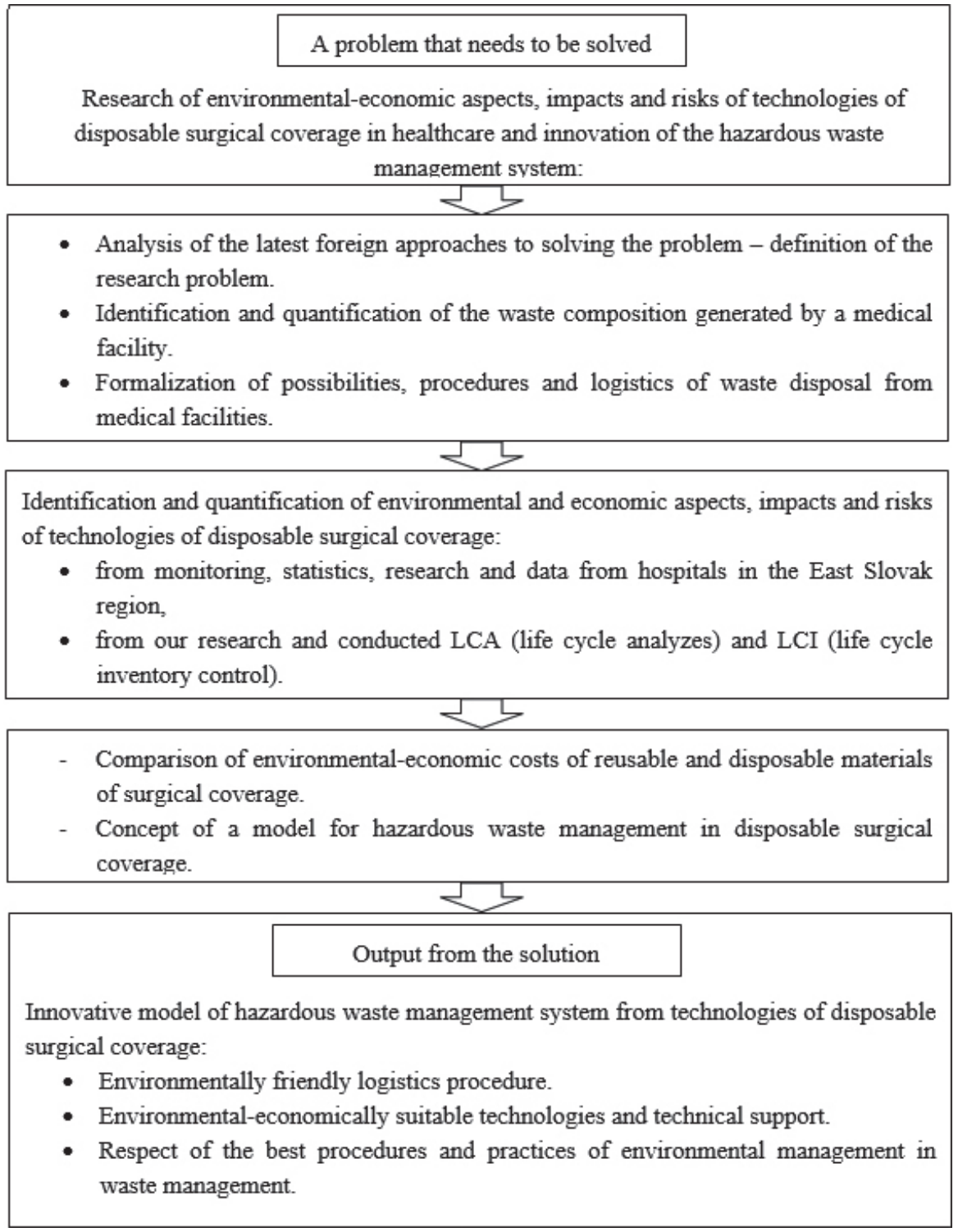

Fig. 1. Flow chart of the proposed methodology. 
of disposable surgical coverage in healthcare points to the necessity to intensify $R \& D$ activities from both perspectives - global and regional. Our research was methodologically conducted as it is shown in Fig. 1.

\section{Results and Discussion}

The largest amount of waste produced by healthcare has a communal character (Fig. 2). Only a certain part is a real threat to the environment. Research shows that with the regular implementation of the waste management program, we can reduce the amount of infectious waste to $5-25 \%$. It depends on the type of equipment and the range of services provided. Infectious hospital waste can also be the waste produced by patients depending on the fact whether the patient suffers from an infectious disease.

Other waste (Fig. 3) does not cause a chemical or biological threat during formation, collection, transport or storage. Disinfection processes are also not required before recycling or disposal. This group includes medical and veterinary waste - non-hazardous, such as surgical instruments, their residues and parts, chemicals and medicines if they do not contain hazardous substances or pathogens.

Waste containers, bins or bags for glass, paper and plastics should be placed in all hospital wards preferably in vestibules near nurses' living rooms. For the collection of metals and aluminium, it is appropriate to place containers at the place of their origin or to reserve the place of collection in selected departments.

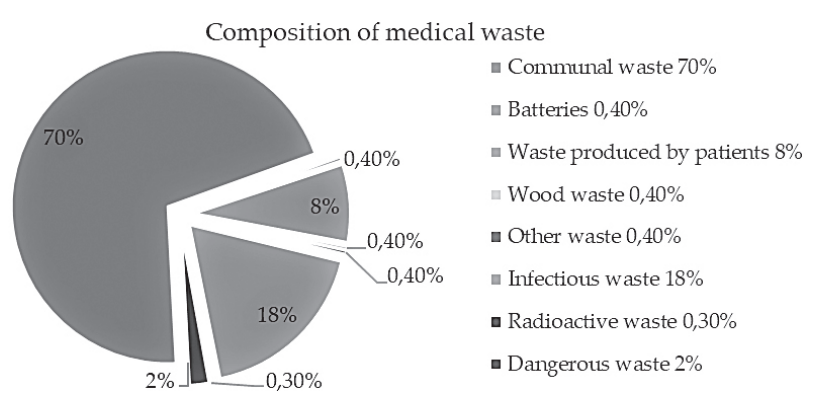

Fig. 2. Composition of medical waste.

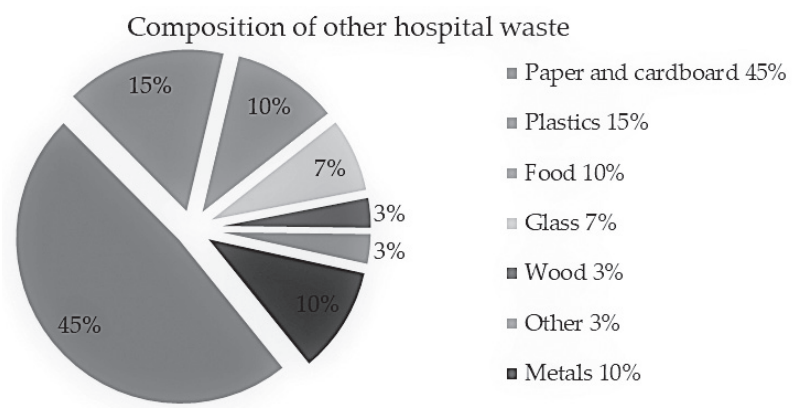

Fig. 3. Composition of other hospital waste.
Location should also be taken into account in order to ensure the possibility of rapid collection of waste from individual departments. It is also important to inform staff about the location of waste containers in the hospital.

Logistics of waste management in hospital facilities must be based on the requirements set out in the Waste Act at all stages of the process, from the generation of waste to its recycling, respectively safety disposal. Procedure for handling of hazardous waste is shown in Fig. 4.

Despite the relatively negligible amount of waste generated in hospitals, this waste is usually associated with strong emotions and concerns from each community. Proper segregation and treatment of hospital waste can lead to very significant cost savings and should be a part of any hospital education program. Currently, there are many options in the hospital waste disposal system. Government regulations and professional association rules help employees to set priority in the environmentally friendly waste management.

Hospital waste accounts show $2 \%$ of national communal waste. Protective gowns and disposable surgical masks represent around $2 \%$ of all hospital waste. Thus, protective gowns and disposable surgical masks represent about $0.04 \%$ of total municipal waste. The possibilities of waste disposal from medical facilities are in Fig. 5 and Fig. 6.

For solid waste and disposable materials, disposal costs are much higher. It is estimated that more than $80 \%$ of regulated hospital waste is disposed of outside the specified European directives. Often, especially disposable materials are included in the increased amount of waste, although in fact it causes the incorrect separation of waste, especially protective gowns and disposable surgical masks, which are contaminated with blood (this waste may or may not represent regulated hospital waste). However, laws, standards and regulations that do not provide detailed guidance on whether blood-contaminated clothing should be considered as regulated hospital waste must be followed.

Regarding waste dump capacity and hospital waste disposal, the number of waste dumps has decreased over the last 10 years, but availability has increased with larger regional waste dumps. It is not yet clear how big is the impact of disposable or reusable materials on the environment - environmental aspects, impacts and risks.

Disposable materials consume more raw materials and energy and generate more solid waste than reusable products. Reusable products consume significantly more water and produce more water pollution by detergents and chemicals. At the same time, they produce more volatile organic compounds than air emissions, which are usually associated with smog levels in the atmosphere. These are advantages and disadvantages for both reusable and disposable systems. In decisionmaking process, the most important thing is to balance 


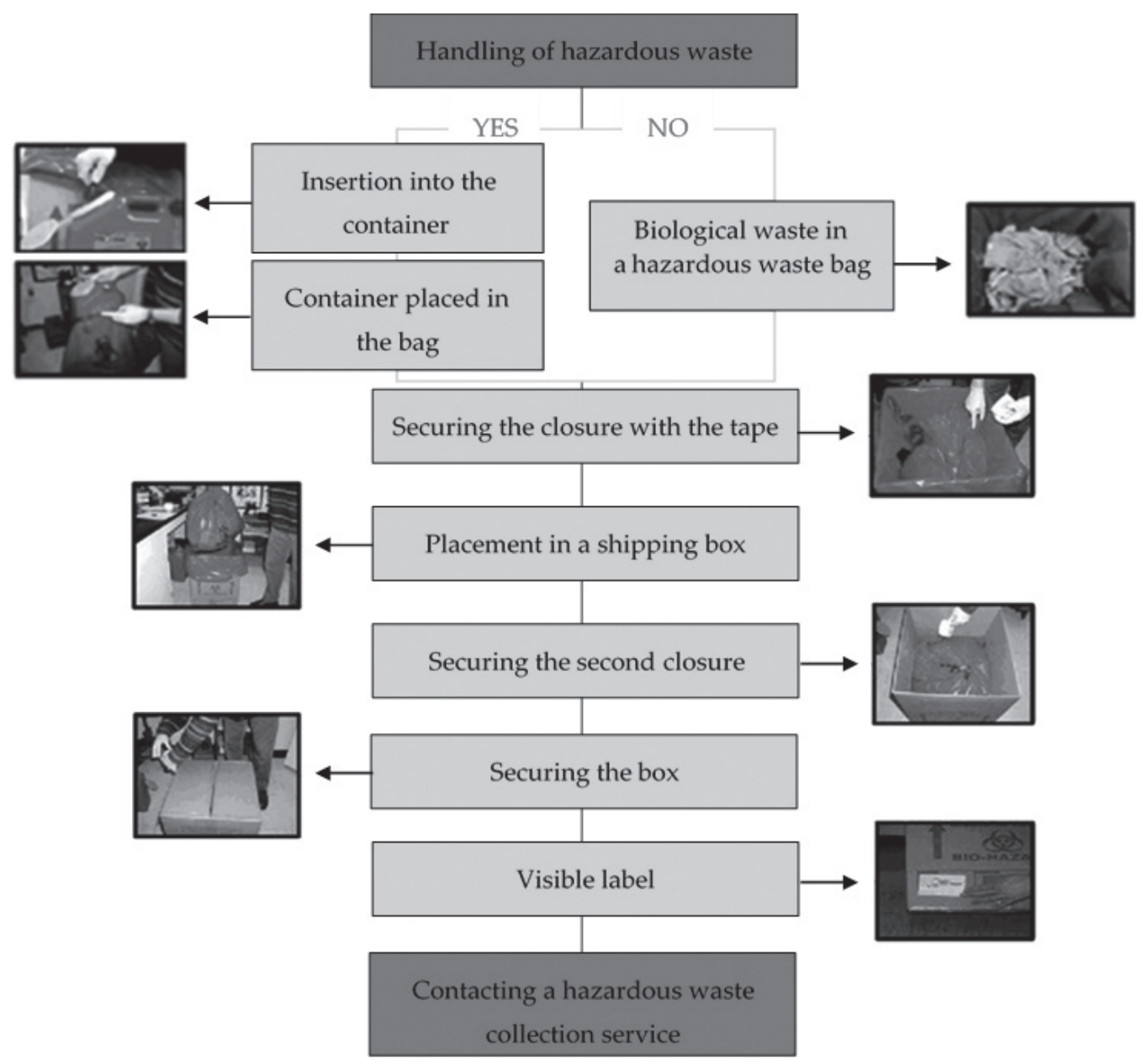

Fig. 4. Procedure for handling of hazardous waste.

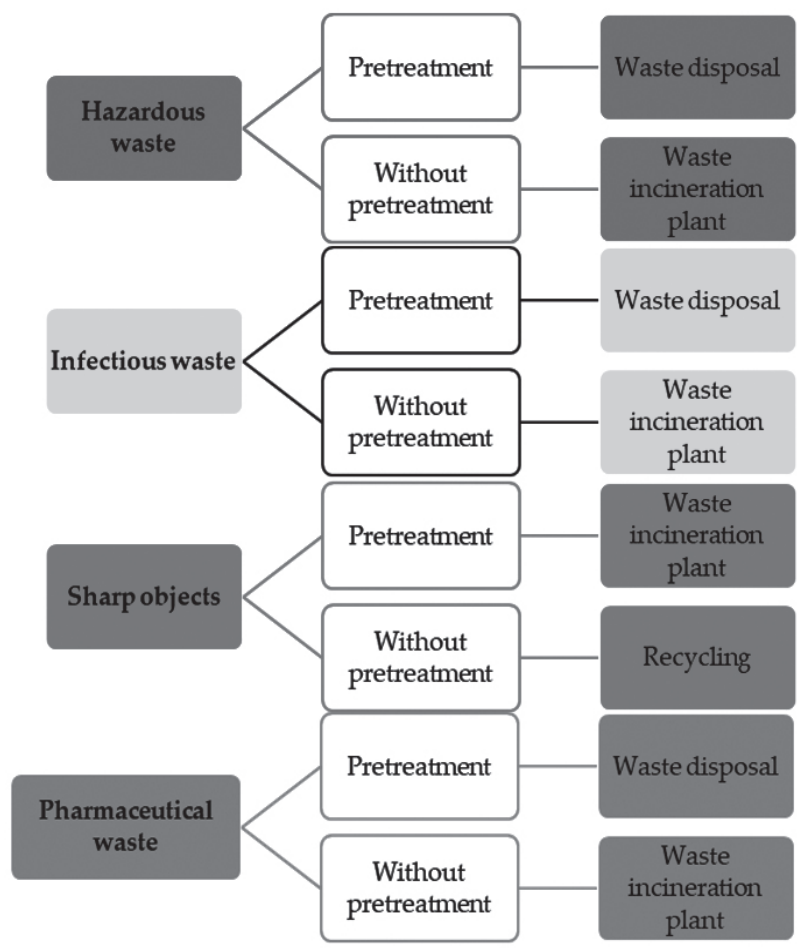

Fig. 5. Structure of OP R\&D at the level of thematic goals (TG) and priority axes (PA). considerations of barrier properties and efficiency, patient and staff safety, infection prevention and environment protection issues.

By disposable surgical masks, the path is much easier in terms of human labour and the technologies used, but it causes increasing of the amount of waste intended for disposal. In relation to the quantification of the environmental quality of variants, interesting results and environmental and health impacts were revealed with analyzes.

These results were obtained from various published monitoring and statistics, as well as from research data obtained in hospitals in the East Slovakia region.

They focus on significant effects on the environment (acidification, Eco toxicity, eutrophication, global warming, ozone depletion, photochemical oxidation) and human health (carcinogenic and respiratory risks). Results according to LCA (Life Cycle Assessment) are in Table 1.

Impacts on human health are shown in graphs in Fig. 7 that is divided into three individual graphs.

Fig. 7 is divided into three graphs. Graphs a) and b) describe the impacts on the population health with compared materials, disposable and reusable material in important stages of their life cycle. 


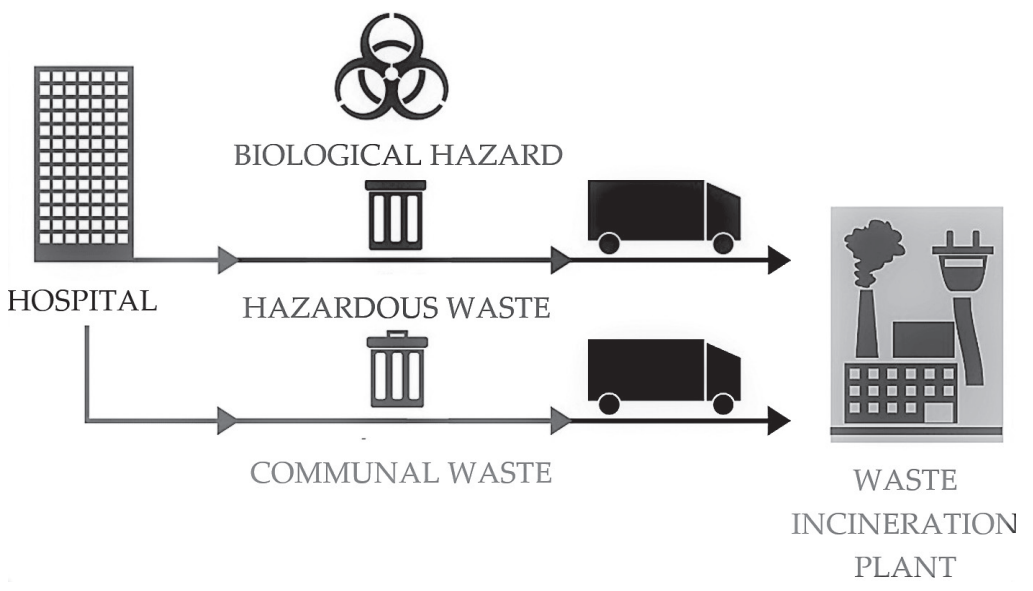

Fig. 6. Graphical representation of the transport of disposable material during hospital surgery.

a)

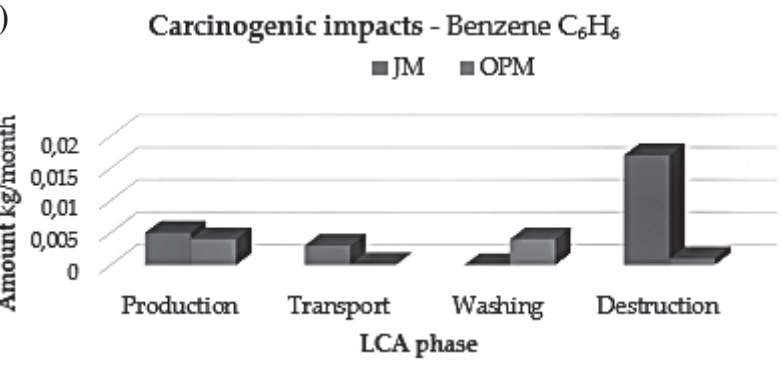

b)

No carcinogenic impacts - Toluene

$\square \mathrm{JM} \quad \square \mathrm{OPM}$

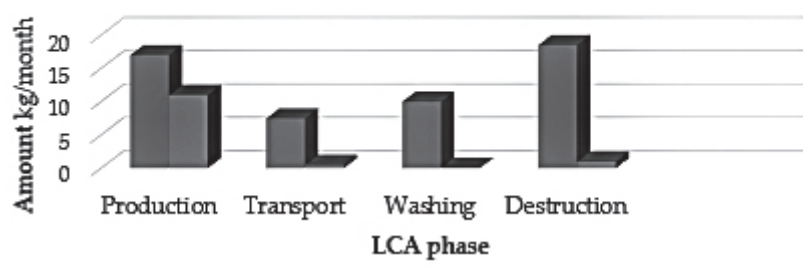

c)

Respiratory risks - PM2, 5-Eq.

$\square \mathrm{MM} \quad \mathrm{OPM}$

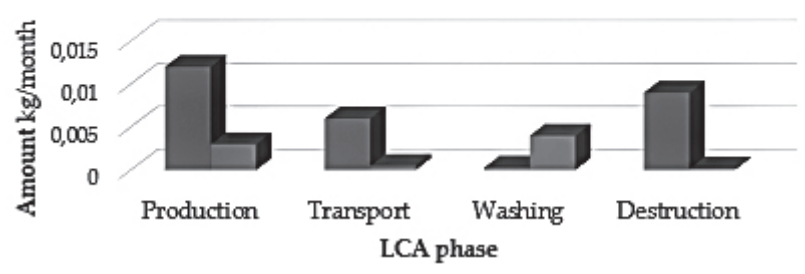

Fig. 7. Impacts on human health.

In the first and second case it is the use of Benzene and Toluene, which are consequence of the combustion process, e.g. pyrolysis. The third graph c) specifies the amount of dust pars generated with an effect on the respiratory organs.

Fig. 8, Fig. 9 and Fig. 10a) and b) represent environmental impacts.

Environmental impacts is registered an increase in the acidity of abiotic components with the participation of hydrogen and dioxins. Dioxins are formed during the combustion of communal, medical or hazardous waste, as well as during the production and combustion of PVC and the bleaching of cellulose with chlorine.

Air pollutants in the form of nitrogen, carbon dioxide, chlorofluorocarbons, sometimes referred to as CFCs and nitrogen oxides, are the main contributors to environmental impacts.

This performed analysis shows that the environmental impacts of reusable materials are more environmentally friendly. Although ten times less emissions are produced, no attribute is mentioned to reduce the transmission of infection.

Nowadays, almost every hospital facility has to calculate the comparison between reusable and disposable items. Many visible and hidden factors must be taken into account. Finding the true lower limit of costs requires an examination of all related costs, some of which may be hidden initially. It is not possible to focus only on usage prices, because there are also other factors that affect overall costs (Fig. 11). In this area, there is scope for the use of the ISO standard.

Table 2 shows the comparison of real costs in three different types of hospitals $(\mathrm{A}, \mathrm{B}, \mathrm{C})$ that work with disposable surgical masks and with cotton surgical masks. Table 3 shows costs of disposable surgical cover

Table 1. Results according to life cycle analysis - LCA.

\begin{tabular}{|c|c|}
\hline Production of $\mathbf{C O}_{2}$ emissions & Content of carcinogenic compounds \\
\hline $3.0 \mathrm{~kg}-$ disposable materials $(\mathrm{JM})$ & $7.9 \times 10^{-3} \mathrm{~kg}-$ disposable materials $(\mathrm{JM})$ \\
\hline $0.3 \mathrm{~kg}-$ reused materials $(\mathrm{OPM})$ & $3.6 \times 10^{-4} \mathrm{~kg}-$ reused materials $-\mathrm{OPM}$ \\
\hline
\end{tabular}


a) Acidification - Moles of hydrogen $\mathrm{H}^{+}$- Eq.

a JM $\square \mathrm{OPM}$

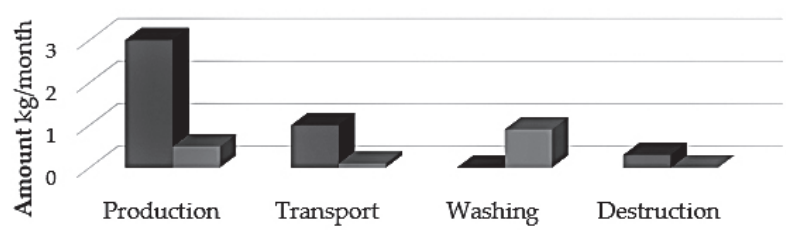

LCA phase

b)

Ecotoxicity - 2,4D (dioxins) - Eq.

$\square \mathrm{JM} \quad \square \mathrm{OPM}$

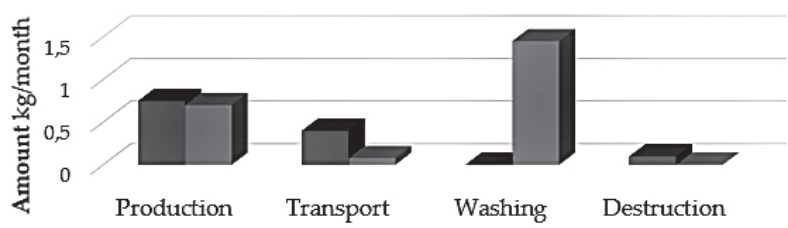

LCA phase

Fig. 8. Environmental impacts I.

a)

Eutrophication - Nitrogen - N

$\square \mathrm{JM} \square \mathrm{OPM}$

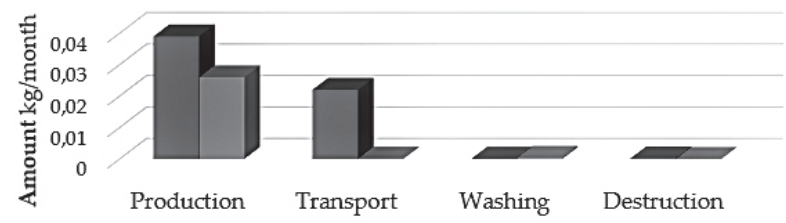

LCA phase

b) Global warming - Carbon dioxide $-\mathrm{CO}_{2}$ aJM $\square \mathrm{OPM}$

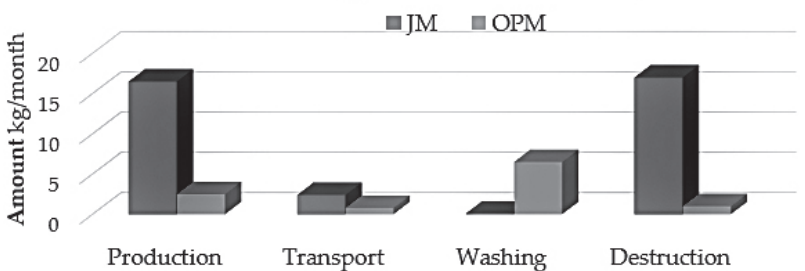

LCA phase

Fig. 9. Environmental impacts II. a) Ozone depletion-CFCs - Chlorofluorocarbons

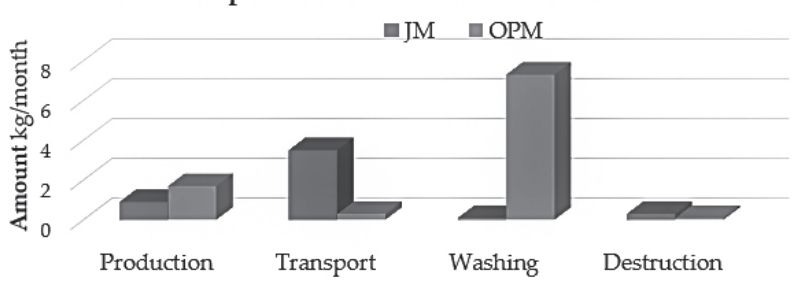

LCA phase

b)

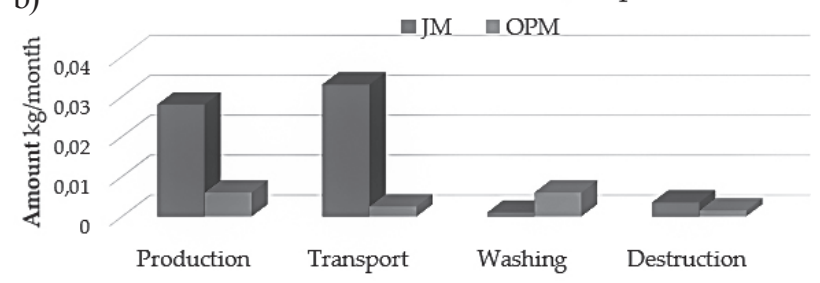

LCA phase

Fig. 10. Environmental impacts III.

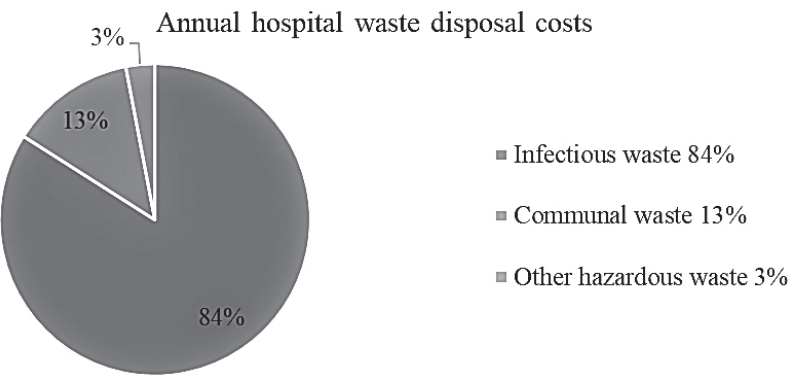

Fig. 11. Annual hospital waste disposal costs.

per one surgical procedure. Table 4 shows costs of reusable surgical cover per one surgical procedure.

Another important factor is the expiration time. While cotton covers and protective gowns in sterile form can be stored maximally 3 weeks, the expiration date of disposable materials ranges from two to five years. Table 5 shows costs of postoperative care in infections

The price of surgery and postoperative care of the easier surgical procedure (e.g. appendicitis) is 400 EUR. In the case of nosocomial infection of the patient, the costs of postoperative treatment is estimated at 668 EUR, which is an increase of more than $50 \%$ of the costs.

Table 2. Comparison of real costs in three different types of hospitals (A, B, C).

\begin{tabular}{|c|c|c|c|}
\hline Hospital & $\mathbf{A}$ & B & $\mathbf{C}$ \\
\hline The number of hospital performance & 3690 & 2352 & 4300 \\
\hline The cost of reusable material, or using only a partial combination & 42 EUR & 30 EUR & 33 EUR \\
\hline Disposable material costs & 25 EUR & 33 EUR & 18 EUR \\
\hline
\end{tabular}


Table 3. Costs of disposable surgical cover per one surgical procedure.

\begin{tabular}{|c|c|c|}
\hline Costs of disposable surgical cover & Costs in EUR \\
\hline Price of a disposable sterile operating set & $25 \mathrm{EUR}$ & 25.00 \\
\hline Weight of operating cover in dry condition & $1.8 \mathrm{~kg}$ & 0.37 \\
\hline Patient masking time */2 people - together & $8 \mathrm{~min}$. & 0.92 \\
\hline Weight of operating cover used & $4.3 \mathrm{~kg}$ & 7.31 \\
\hline Waste handling * & $20 \mathrm{~min}$. & $1.7 \mathrm{EUR} / \mathrm{kg}$ \\
\hline Transportation of hazardous waste and disposal & 0.05 & $\mathbf{3 3 . 6 0}$ \\
\hline *average salary of medical staff per minute & & \\
\hline Total & & \\
\hline
\end{tabular}

* Calculated average salary of middle medical staff $-500 \mathrm{EUR} / \mathrm{month}=0.046 \mathrm{EUR} / \mathrm{min}$

Table 4. Costs of reusable surgical cover per one surgical procedure.

\begin{tabular}{|c|c|c|}
\hline Costs of reusable surgical cover & Costs in EUR \\
\hline Weight of operating cover in dry condition & $8.5 \mathrm{~kg}$ & \\
\hline Patient masking time * / people - together & $15 \mathrm{~min}$. & 1.20 \\
\hline Weight of operating cover used & $12 \mathrm{~kg}$ & 1.48 \\
\hline Waste handling * & $40 \mathrm{~min}$. & 42.00 \\
\hline Overhead costs for energy, water, washing, sterilization and ironing * & $0.7 \mathrm{EUR} / \mathrm{min}$. & 0.66 \\
\hline Workforce for sorting clean and dirty laundry - 20 min./performance & $0.037 \mathrm{EUR} / \mathrm{min}$. & 0.74 \\
\hline Time of folding, packing and preparing laundry for sterilization & $20 \mathrm{~min}$. & 46.08 \\
\hline Total & & \\
\hline
\end{tabular}

* This sum is the actual average of the overhead costs given according to the calculations of the specific hospital.

Calculated average salary of middle medical staff $-400 \mathrm{EUR} / \mathrm{month}=0.037 \mathrm{EUR} / \mathrm{min}$. The summary does not include:

- initial investment in the purchase of cotton surgical masks of various sizes,

- bags required for packaging sterile laundry,

- time necessary to properly folding and preparation of the laundry for sterilization,

- time required for handling the laundry before the operation,

- transport, driver's salary and vehicle down payment due to different types of layout monoblock/pavilion type,

- costs of storage facilities and their volume at entry and exit.

Barrier protection for both the patient and the staff should play the most important role in choosing the method of surgical masks use. This is true for both surgery or for contact with a possible infection. Choosing the right solution that is appropriate for the

Table 5. Costs of postoperative care in infections.

\begin{tabular}{|c|c|}
\hline $\begin{array}{c}\text { Costs of postoperative care for nosocomial } \\
\text { infection }\end{array}$ & Costs in EUR \\
\hline Accommodation of the patient -7 days & 200.00 \\
\hline Surgical examination & 26.00 \\
\hline Antibiotic treatment, sampling & 27.00 \\
\hline RTG/USG & 15.00 \\
\hline Disposable material costs & $\mathbf{2 6 8 . 0 0}$ \\
\hline
\end{tabular}

environment, economic opportunities and health is very important.

The safe and economical treatment, processing and disposal of biohazardous waste is a worldwide issue. Autoclaves are a solution for a more environmentally friendly approach. They are a non-combustion technology that complies with current legislation and can minimize the amount of contaminated waste and transform it into communal waste, which poses much less risks. Hospital autoclaves have gone through a long phase of development. In 1879, Charles Chamberland invented high-pressure steam sterilization. Since then, autoclaves have undergone many technical changes, and now the industry offers us a new solution for the treatment of hospital waste. Table 6 shows the investment costs for incinerator and autoclave, which processes $25-40 \mathrm{~kg} /$ hour that were developed by the US market. 
Table 6. Investment costs for incinerator and autoclave in EUR.

\begin{tabular}{|c|c|c|}
\hline Item & Incinerator & Autoclave \\
\hline Basic equipment & 114780 & 53564 \\
\hline Installation costs & 17217 & 4974 \\
\hline Equipment costs to capture gas emissions to meet the limit set by the US EPA & 148449 & 0 \\
\hline Steam generator costs & 0 & 12243 \\
\hline Costs of monitoring and measuring emissions & 12702 & 1836 \\
\hline Total & $\mathbf{2 9 3 \mathbf { 1 4 8 }}$ & $\mathbf{7 2 ~ 6 1 7}$ \\
\hline
\end{tabular}

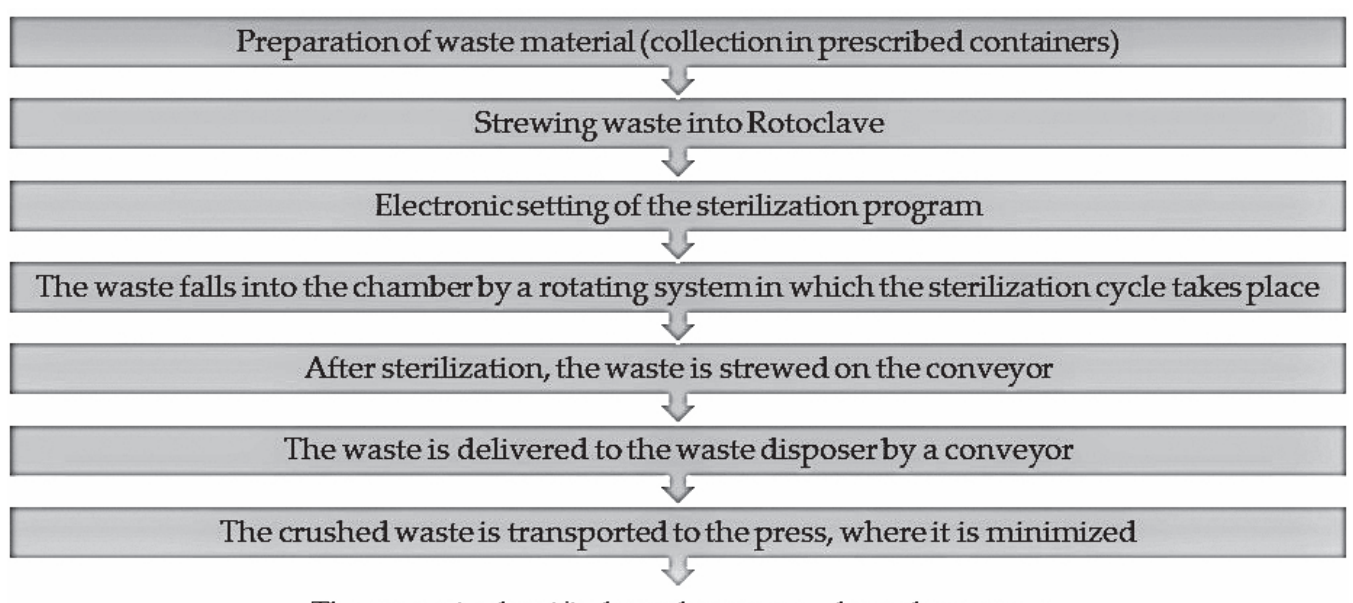

The waste is classified as other waste- harmless waste

Fig. 12. Hazardous waste management system from disposable surgical masks.

In the proposed concept of processing waste from disposable materials, hazardous waste that undergoes the sterilization process becomes communal waste, which will significantly reduce the economic costs, which are 50 times higher in the disposal of hazardous waste than in communal waste. This concept also reduces risks arising from the handling of hazardous waste.

Fig. 12 describes the whole system how the waste is processed and subsequently minimized. This proposed

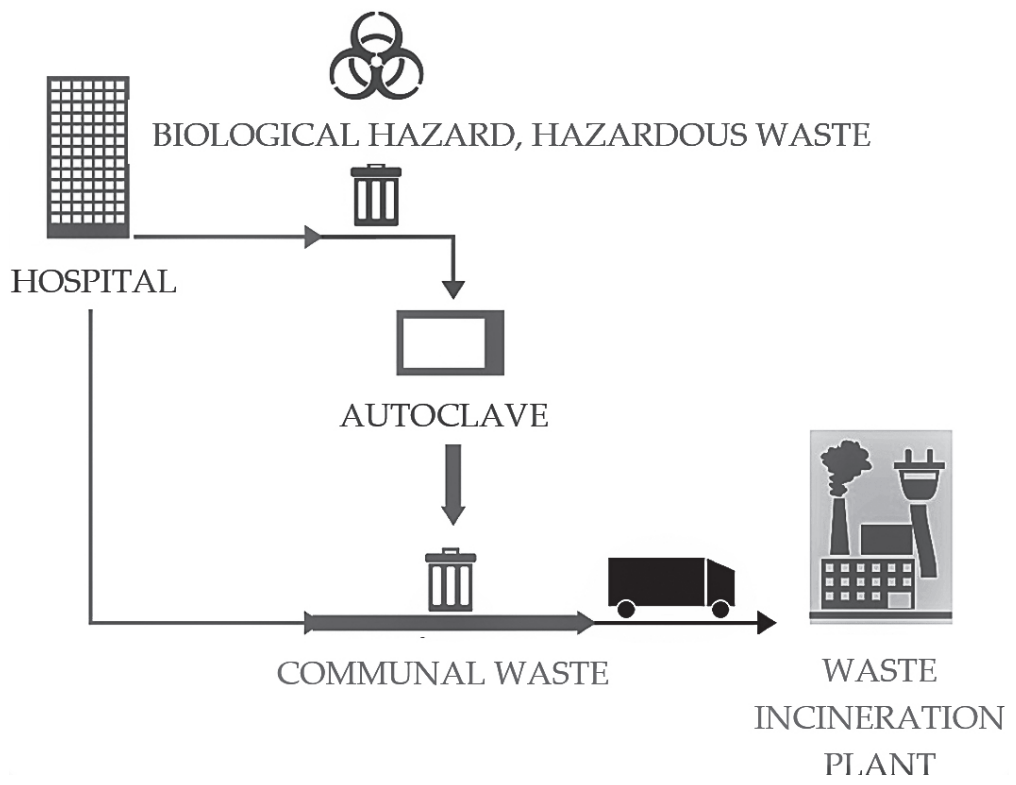

Fig. 13. Proposed concept of processing disposable material. 
solution largely addresses the issue of pollutant production in the combustion of hazardous waste from hospital facilities and brings an economic effect.

Fig. 13 shows a graphical representation of the proposed concept of processing disposable material.

The following illustration reflects easy operation, operator safety and contactless operation, and guarantees successful final sterilization and disposal of hazardous waste.

\section{Conclusions}

Disposable materials in the production of surgical masks use more raw materials and energy and generate more solid waste than reusable products. Reusable products consume significantly more water and pollute water largely with detergents and chemicals. Many volatile organic compounds are also formed and these compounds affect the atmosphere. These are advantages and disadvantages for both reusable and disposable systems.

It is difficult to control costs and assess them accurately. A comprehensive cost assessment requires an examination of all related costs, some of which may be initially hidden. Credible cost conclusions are difficult to process due to the different structures and capabilities of hospitals as well as the financial resources available. Training programs for the proper separation of waste from other hospital waste should make a significant contribution to the reduction of disposal costs in many institutions.

In decision-making process, the most important thing is to balance considerations about barrier properties and efficiency, patient and staff safety, infection prevention and environmental protection issues. The solution are non-combustion methods for the disposal of hazardous waste, which require higher input costs, but ultimately bring greater financial and environmental effects.

The current mission of medical facilities in the field of waste management should be a selection of the proper solution, which harms the environment as little as possible and does not threaten human health, in accordance with the legislation.

\section{Acknowledgements}

This research was funded by KEGA, grant number KEGA 032EU-4/2020, 002TUKE-4/2020 and 043ZU$4 / 2019$

\section{Conflict of Interest}

The authors declare no conflict of interest.

\section{References}

1. LAUSTSEN G. Reduce-Recycle-Reuse: Guidelines for promoting perioperative waste management. AORN Journal, 85, 717, 2007.

2. YOU S., SONNE C., OK Y.S. COVID-19: Resource recovery from plastic waste against plastic pollution. Cogent Environmental Science, 6, 2020.

3. KLEMES J.J., VAN FAN Y., TAN R.R., JIANG P. Minimising the present and future plastic waste, energy and environmental footprints related to COVID-19. Renewable and Sustainable Energy Reviews, 127, 2020.

4. RHEE S.W. Management of used personal protective equipment and wastes related to COVID-19 in South Korea. Waste. Manage. Res. 38, 820, 2020.

5. MIHAI F.C. Assessment of COVID-19 waste flows during the emergency state in romania and related public health and environmental concerns. International Journal of Environmental Research and Public Health, 17, 2020.

6. DAS A., GARG R., OJHA B., BANERJEE T. Biomedical Waste Management: The Challenge amidst COVID-19 Pandemic. Journal of Laboratory Physicians, 12, 161, 2020.

7. SARKODIE S.A., OWUSU P.A. Impact of COVID-19 pandemic on waste management. Environment, development and sustainability, 1, 2020.

8. SINGH N., TANF Y., ZHANG Z., ZHENG C. COVID-19 waste management: Effective and successful measures in Wuhan, China. Resources, Conservation, and Recycling, $163,2020$.

9. RUPANI P.F., NILASHI M., ABUMALLOH R.A., ASADI S., SAMAD S., WANG S. Coronavirus pandemic (COVID-19) and its natural environmental impacts. International Journal of Environmental Science and Technology, 1, 2020.

10. SHARMA H.B., VANAPALLI K.R., CHEELA V.S., RANJAN V.P., JAGLAN A.K., DUBEY B., GOELS., BHATTACHARYA J. Challenges, opportunities, and innovations for effective solid waste management during and post COVID-19 pandemic. Resources, conservation and recycling, 162, 2020.

11. TABISH M., KHATOON A., ALKAHTANI S., ALKAHTANE A., ALGHAMDI J., AHMED S.A., MIR, S.S., ALBASHER G., ALMEER R., AL-SULTAN N.K., ALJARBA N.H., AL-QAHTANI W.S., AL-ZHARANI M., NAYAK A.K., HASNAIN M.S. Approaches for prevention and environmental management of novel COVID-19. Environmental Science and Pollution Research, 1, 2020.

12. ILYAS S., SRIVASTAVA R.R., KIM H. Disinfection technology and strategies for COVID-19 hospital and bio-medical waste management. Science of the Total Environment, 749, 2020.

13. ZAND A.D., HEIR A. V. Environmental impacts of new Coronavirus outbreak in Iran with an emphasis on waste management sector. Journal of Material Cycles and Waste Management, 1, 2020.

14. NZEDIEGWU C., CHANG S.X. Improper solid waste management increases potential for COVID-19 spread in developing countries. Resources, Conservation, and Recycling, 161, 2020.

15. PENG J., WU X., WANG R., LI C., ZHANG Q., WEI D. Medical Waste Management Practice during the 20192020 Novel Coronavirus Pandemic: Experience in a General Hospital. American Journal of Infection Control, 48, 918, 2020. 
16. RADA E.C., MAGARIL E.R., SCHIAVON M., KARAEVA A., CHASHCHIN M., TORRETTA V. MSW Management in Universities: Sharing Best Practices. Sustainability, 12, 2020.

17. CESARO A., PIROZZI F. About the effects of COVID-19 on solid waste management. TeMA-Journal of Land Use, Mobility and Environment, 59, 2020.

18. RAGAZZI M., RADA E.C., SCHIAVON, M. Municipal solid waste management during the SARS-COV-2 outbreak and lockdown ease: Lessons from Italy. Science of the Total Environment, 745, 2020.

19. YU H., SUN X., SOLVANG W.D., ZHAO X. Reverse Logistics Network Design for Effective Management of Medical Waste in Epidemic Outbreaks: Insights from the Coronavirus Disease 2019 (COVID-19) Outbreak in Wuhan (China). International Journal of Environmental Research and Public Health, 17, 2020.
20. KUMAR H., AZAD A., GUPTA A., SHARMA J., BHERWANI H., LABHSETWAR N.K., KUMAR R. COVID-19 Creating another problem? Sustainable solution for PPE disposal through LCA approach. Environment, Development and Sustainability, 1, 2020.

21. LIU Z., LI Z., CHEN W., ZHAO Y., YUE H., WU Z. Path Optimization of Medical Waste Transport Routes in the Emergent Public Health Event of COVID-19: A Hybrid Optimization Algorithm Based on the Immune-Ant Colony Algorithm. International Journal of Environmental Research and Public Health, 17, 2020.

22. PRATA J.C., SILVA A.L., WALKER T.R., DUARTE A.C., ROCHA-SANTOS T. COVID-19 pandemic repercussions on the use and management of plastics. Environmental Science \& Technology, 54, 7760, 2020. 